REVISTA DE DERECHO UNED, núm. 2, 2007

\title{
NOTAS ACERCA DE SI SAN ISIDORO USÓ LOS TEXTOS JUSTINIANEOS
}

\author{
Ramón J. Fernández de Marcos Morales ${ }^{1}$
}

Resumen: El derecho justinianeo no tuvo una influencia inmediata, pero - sin duda - la España visigoda conoció las fuentes justinianeas. De hecho, tal y como se intenta poner de manifiesto en este trabajo, el derecho justinianeo fue aplicado y conocido en España, por los legisladores y jurisconsultos visigodos. Así, pues, resulta imposible que San Isidoro desconociese las colecciones justinianeas.

El presente estudio ofrece datos y testimonios de los que cabe razonablemente deducir que el Doctor de las Españas conoció y estudió los textos justinianeos, de manera que si el Metropolitano de la Bética no hizo utilización más precisa de los mismos no fue por desconocimiento de las mismas, sino intencionadamente. El estudio continúa analizando los posibles motivos que podrián haberle impulsado a no referirse a las fuentes justinianeas, y en cambio a citar a Justiniano como teólogo y no como legislador.

San Isidoro de Sevilla, realizó el primer ensayo de literatura teológica del que se tiene conocimiento, y presentó a la España visigoda la Hispana, colección canónica que tuvo fuerza de ley en la península hasta el siglo XII, además estableció que el rey debía arrodillarse delante de los obispos, y los obispos debían ponerse de rodillas delante del rey, tal y como sucedió en los últimos concilios de Toledo. Más tarde, a finales del siglo VIII, cuando Carlomagno llamó a su corte a Alcuino de York, éste utilizó la Hispana y el texto isidoriano de la Biblia, como ayuda para cambiar los signos de las iglesias carolingias, quedando fijada para siempre la impronta isidoriana.

1 Ramón J. Fernández de Marcos Morales, Doctor en Derecho y Profesor Asociado de Derecho Romano de la Universidad Nacional de Educación a Distancia. 
Abstract: The justinianean law hadn't an inmediate influence, but undoubtedly - visigothic Spain knews justinianean sources. In fact, as it makes clear in this essay, the Byzantine or justinianean law was applied and known in Spain, by visigothics legislators and jurisconsultos. So it turns out impossible that St. Isidoro didn't knows the justinianean collections.

In this essay it has been proved that the Doctor of Spains knews the justinianean texts, and there was no ignorance for his part, so that if the metropolitan of the Andalusia didn't use the important justinianean sources, it wasn't through ignorance, itself, but deliberately. The study still analyses the possible reasons that droves him to don't use the justinianean sources, and to quote justinianean only as a theologian, and not as a legislator.

St. Isidoro of Seville, carried out the first essay of theological literature has been notice, and showed the Hispanic to visigothic Spain, canonical collection that had force of the law in the Iberian peninsula until the twelfth century, also he layed down that the king should be kneeling in front of the bishops, and the bishops should be kneeling in front of the king, as happened at the last councils of Toledo. Later, at the end of the seventh century, when Charlemagne called to his court to Alcuino of york, this one used the Hispanic and St. Isidoro's text of the Bible, like help to change the Carolingian churches signs, and it was established forever the isidorian impression.

Sumario: 1. INTRODUCCIÓN.-2. LA HISPANIA VISIGODA.-3. LA BIBLIOTECA ISIDORIANA.-4. LA TEOLOGÍA ISIDORIANA.-5. A MODO DE CONCLUSIÓN

\section{INTRODUCCIÓN}

Todos los prestigiosos investigadores que han analizado la figura de San Isidoro, coinciden en que la cultura de Occidente está en deuda con él porque, cuando se derrumbó la inmensa construcción jurídica y política del imperio romano, se encargó de compilar todos los conocimientos que la humanidad había adquirido a lo largo de doce siglos. No podemos decir que fuera un mero compilador enciclopédico, que elaboró un inmenso fichero y luego lo plasmó en sus obras, porque, en primer término, abarcó todas las ramas conocidas del saber: la astronomía, las ciencias naturales, la cosmografía, el derecho, la filosofía, las físicas, la geometría, la historia, la música, la poesía, la política, la religión, o la teología; y en segundo lugar, en to- 
das sus obras, a menudo, encontramos observaciones personales que solo pueden ser fruto del amor a la ciencia y del profundo conocimiento adquirido.

No obstante, se suscita un interesante particular, y es que no existe unanimidad, entre los juristas que han estudiado acerca de la cuestión de si San Isidoro usó los textos justinianeos. El elenco es numeroso $^{2}$ en ambas posiciones, entre los que lo niegan, destacan Savigny y Kübler, y entre los que lo afirman, Ureña y Riaza. En este sentido, el presente trabajo pretende arrojar algo de luz -con mayor o menor acierto- sobre esta difícil, pero estimulante controversia.

Kübler, en Isidorusstudien ${ }^{3}$, afirma que San Isidoro usó únicamente obras prejustinianeas, pero, como establece Ureña, no es posible negar que la obra legislativa de Justiniano ${ }^{4}$ fue conocida en la España Goda, entonces, por qué San Isidoro de Sevilla únicamente menciona a Justiniano como teólogo ${ }^{5}$ y no lo incluye entre los grandes legisladores, y además, en la enumeración de las fuentes, se detiene en el Código de Teodosio ${ }^{6}$. En el Doctor de las Españas, resulta impensable este desconocimiento, para no ser, como sostiene Ureña ${ }^{7}$, intencional.

Como podemos apreciar, la cuestión, ampliamente discutida por la doctrina ${ }^{8}$, no es baladí, ni tampoco podemos pretender resolverla

2 Resulta un dato curioso, que casi todos los juristas que lo han afirmado sean españoles (Ureña, Riaza, De Diego, Pou y Ordinas), y la mayoría de los juristas que lo han negado sean extranjeros (Savigny, Kübler, Dirksen, Conrat).

3 Vid. Hermes $X X V, 1890$, p.496 y ss.

${ }^{4}$ Durante el reinado de su tío Justino (518-527), Justiniano concibió su reunión de leges, y una vez Emperador de Oriente durante los años 527 al 565, llevó a cabo su gran obra codificadora, así el 9 de abril del año 529 publicó el Codex de Justiniano, el 21 de noviembre del año 533 promulgó, mediante la constitución imperatoriam las Institutiones, el 16 de diciembre del año 533 promulgó, por la constitución Tanta el Digesta, que se conserva casi íntegramente (sólo falta un folio), gracias al manuscrito de Pisa, del siglo VI, actualmente conservado en la Biblioteca Mediceo-Laurenciana de Florencia, conocido como Littera Florentina. Esta impresionante codificación, la realizó el emperador Justiniano (como señala ARANGIO-RUIZ, Vicente, Historia del Derecho Romano, Madrid 1987, p.319 y ss.), en el breve espacio de seis años, pero no por ello cesó en su actividad legislativa, así durante los treinta años siguientes publicó también un gran número de Novellae.

5 Cfr. De viris illustribus, cap.XXXI

${ }^{6}$ Cfr. Etymologiarum, lib.V, cap.I

7 Vid. UREÑA, Rafael de, Historia de la Literatura jurídica española, Tomo I, Volumen I, Madrid 1906, p.300

${ }^{8}$ Cfr. D’ORS, Alvaro, La singularidad de España, Revista de Estudios Histórico-jurídicos XIII, 1989-1990, p.156 y ss.; FUENTESECA, Pablo, Historia del Derecho Romano, Madrid 1987 p.318 y ss.; o más recientemente RIAZA, Román (autor secunda- 
en un trabajo de estas características, pero si dar unas notas $u$ opiniones personales que, obviamente, tienen lugar ante un hecho jurídico de esta magnitud, lo mismo que cuando contemplamos una obra maestra, un cuadro por ejemplo, a cada uno, nos produce impresiones diferentes, sin que por ello estemos ninguno en posesión de la verdad o de los misterios que la originaron o que hicieron que se desarrollase así, tal cual hoy podemos contemplarlo.

En suma, nos preguntamos en primer lugar, si San Isidoro conoció los textos justinianeos, y en segundo lugar, si - como parece-los conoció, por qué no los utilizó.

\section{LA HISPANIA VISIGODA}

El mosaico prerromano estaba integrado por tribus celtas, iberas, y mestizas, como los astures, bastetanos, cantabros, celtiberos, edetanos, galaicos, ilergetes, lusitanos, turdetanos, y vacceos ${ }^{9}$, es decir, Iberia era un puzzle de tribus, que no aceptaban autoridades más allá de sus fronteras, pero para librarse del dominio cartaginés, España abandonó sus anteriores señas de identidad y se inclinó por los romanos, así, pasó de Iberia a Hispania.

Al inicio de la Edad Media, España había adoptado, pues, el latín como lengua, la literatura latina como literatura, y todas sus instituciones eran ahora romanas, es decir, España estaba totalmente romanizada, pero, al contrario que otros países, conservó su cultura romana, especialmente en el sur, donde muchas ciudades se resistieron a la dominación germánica, hasta el reinado de Leovigildo (572-586). Además, los nuevos invasores se mostraron civilizados, en gran parte, porque llevaban varias generaciones en contacto con Roma.

En el año 552, el rey legítimo Agila, arriano, expulsa de Cartagena a su rival Atanagildo, noble visigodo apoyado por los cristianos. Atanagildo pide ayuda a los bizantinos ${ }^{10}$, que han dominado ya el norte de África, y el emperador de Constantinopla, Justiniano, envía

rio SORIA SESÉ, Lourdes), en INTERPRETATIO, Revista de Historia del Derecho V (1998), p.32, donde todavía se mantiene, sin cerrar, la discusión acerca de si San Isidoro utilizó las compilaciones justinianeas.

9 Vid. Historia y Vida, n. ${ }^{\circ} 435$, junio 2004, p.35.

10 A la muerte de Teodosio I el Grande (395 d.C.), emperador de origen hispano, el imperio romano quedó dividido definitivamente en una mitad oriental que perviviría hasta 1453 con el nombre de Bizancio, y otra occidental, que sucumbirá a las invasiones bárbaras en el siglo $\mathrm{V}$. 
una flota imperial que se apodera de Cartagena y otros puertos del Mediterráneo. Al año siguiente, Agila es apuñalado en un banquete, y Atanagildo se constituye en rey indiscutible, pero Justiniano se niega a abandonar las plazas ocupadas y un gran número de familias poderosas e influyentes, tienen que abandonar la ciudad. Entre ellos estaba el patricio hispanorromano Severiano ${ }^{11}$, de religión católica, que con su mujer, de estirpe goda y de religión arriana ${ }^{12}$, y sus hijos Leandro, Fulgencio y Florentina, marcharon a Sevilla, donde parece que entre el año 556 y $560^{13}$, nace su cuarto hijo, el menor de ellos, Isidoro.

Como podemos apreciar, cuando nace Isidoro, las tropas bizantinas han ocupado el sudeste de España, por lo que las relaciones entre la Península y el centro de la vida cultural del momento que, como es bien sabido, estaba en Constantinopla, se incrementaron notablemente. Así, pues, el legislador de Sevilla, no deseaba ser hispano-bizantino, pero no por cuestiones personales (de hecho, San Isidoro firmó, en el III Concilio de Toledo, que es en Toledo donde debe residir el metropolitano de Cartagena, sometiendo así a la ciudad de sus padres), sino por razones mucho más poderosas, como su idea fija de la unidad de la iglesia nacional y otras, que analizaremos más adelante con detalle.

En este orden de cosas, no extraña que el reino visigodo tuviera, hasta el 624, como tarea prioritaria y permanente, expulsar a los bizantinos y recuperar el territorio ocupado, pero durante la ocupación bizantina, Justiniano, como sostiene Gibert ${ }^{14}$, habría intentado introducir oficialmente sus compilaciones legales en la Cartaginense y en la Bética.

Sabemos de la dominación bizantina en la España visigoda (en las costas orientales, en las baleares y en otras partes del territorio), entre los años 550 y 624, pero no conocemos del influjo jurídico de su derecho, del derecho justinianeo. El problema es importante, porque no tenemos ningún documento directo o los existentes son nulos en el orden jurídico.

11 Alto funcionario del rey godo en aquella región y, probablemente, de gran influencia, ya que sus tres hijos varones fueron obispos.

${ }^{12}$ Cfr. PÉREZ DE URBEL, Justo, San Isidoro de Sevilla. Su vida, su obra y su tiempo, León 1995, p.21.

${ }^{13}$ Cfr. QUILES, Ismael, San Isidoro de Sevilla, Buenos Aires 1945, p.15.

14 Cfr. GIBERT, Rafael, Elementos formativos del Derecho en Europa. Germánico, Romano, Canónico, Granada 1976, p. 29. 
Una prueba de la aplicación y el arraigo que tuvo en España la legislación bizantina, podría encontrarse en la Ley 10, de Recesvinto ${ }^{15}$ (653-672) "de remotis alienarum gentium legibus», en la demostración de esta ley dada contra la legislación bizantina donde, 30 años después de ser expulsados, aún se sentía la necesidad de una acción enérgica.

Efectivamente, la ley décima, habla de gentes alienae (de remotis alienarum gentium legibus). No sin razón se objeta que no podían llamarse tales, en el Reino Visigodo, los hispano-romanos. Sería también extraño que con esa rúbrica («de remotis alienarum Pentium legibus") se indicase la Lex Romana Visigothorum, que era una ley interna cardinal del Estado, y más bien parecía natural que ella se refiriese a leyes externas o extranjeras, pertenecientes a gentes que no formaban parte del Reino visigodo, es decir, hacía referencia al derecho justinianeo.

El Cardenal Arcadio Larraona y el Obispo Arturo Tabera, encontraron más de veinte reminiscencias textuales -más de las que admitía Savigny - y otras muchas que contienen la máxima o el principio romano, que prueban ${ }^{16}$ que los jurisconsultos visigodos conocieron las fuentes justinianeas $y$, aunque no las usaron abundantemente, si las utilizaron ocasionalmente.

${ }^{15}$ Vid. LARRAONA y TABERA, Congresso Internazionale di Dirito Romano, Istituto di Studio Romani, Roma 1935, p. 91-92.

${ }^{16}$ Cfr. Lex,V., II,I,15 = C.Iust.III,1,14,1; D.5,1,81 (Ulp.); Lex,V., II,I,30 = Nov. 86, 1,3; Lex,V.,II,3,36 = C.Iust.II,12,21; Lex,V.,II,3,7 = C.Iust.IV,35,17; D.17,1,56,3; Lex.V., II,3,9 = C.Iust. II, 13; Lex. V., II, 4,2 = C.Iust. IV,20,16 pr.; Lex.V., II,4,1 = D.3,2,1; Lex.V., II,4, 3 = Nov.Iust. 73,1; 90,1; D.22,5,3 pr.; Lex.V.,II, 4,5 = D.22,5, 3,4; C.Iust.IV,20,16,1;Ibid.21,18; Nov.90,5; Lex.V.,II,5,7 = D.2,14,27,4; 45,1,26; 17,1,6,3; Lex.V.,II,5,11 = C.Iust.VI,22,9; Lex.V.,II,5,17 = Nov.Iust. 73,7,3; C.Iust.IV,21,16; Lex.V., III, 1,9 = Nov.Maior.,6,9; Lex.V., III,2,1 = C.Iust. V,9,2 (C.Th.III,8,1); VI,56,4; Lex.V.,III,2,6 = D.48,5,12,12; Nov.Iust.97, (98), II; L.V., III,3 rubric. = C. Th.DX,24; L.V., III,3,2 = C.Th.IX,24,1; Lex.V., III,3, 6 = C. Iust.IX,13,1,1; Pauli Sent. V., 23,8; Lex. V., III,6,2 = Nov. Iust.117,9,3; Lex. V., IV, 5,5 (de peculio castrensi) = C. Th. VI, 35, 15; C.Iust.,V., V,7,7 = Pauli Sent. V,1,4; Lex., V., VI,1,8 = D. 48,4,11; 19,20; Lex. V., VI,4,6 = C.Iust.IX,16,2; Lex.V.,VI,5,2 = D.48,8,1,3,7; Pauli Sent.V.,23,12,13; Nov.Val.III,19; Collat.1,6-10; Lex.V., VI,5,3 = D.48,8,7; Lex.V., VI, 5,10 = Collat.1,10; Lex.V.,VI,5,18 = Pauli Sent. V,24; C.Th. IX, 15, 1; Lex.V., VII, 2, 10 = Pauli Sent. V. 27; Lex.V., VII, 5, 1 2 = Pauli Sent. V., 25, 1; Lex.V., VII,5,2 = C. Iust. IV, 20, 18; 21, 4-8; Lex.V., VII 5, 4-6 = Pauli Sent. V. 25,6,7,10, 11; Lex. V., VII, 6, 3 = Pauli Sent. V.25,5; Lex.V., VIII, 1,3 = Pauli Sent. V.,3,1; Lex.V., VIII,2,1 = Pauli Sent. V.3,6; D.48,19,28, 12; Lex. V., VIII,4,2 = D.47,2,40; Lex.V., VIII, 4,12 = Pauli Sent. 1,15,15,3; Lex. V., VIII, 1, 23 = D.9,2,28,29 pr.; Lex.V., IX, 1,1 = C. Iust. VI, 1,5; C.Th. V, 9, 1-2 (Eurico); Lex.V.IX, $12=$ C.Iust.VI,1,4; Lex.V., IX.1, 11 =C.Iust. VI, 1,4; Lex. V,IX,3,2 = C.Th.IX.45,3; Lex.V., IX, $3,4=$ C.Th. IX, 45, 1; Lex. V., X,1,4 = C.Th.XI, 26,2; Lex.V., X.1,17 = Nov. 156,1; 162,3; C.Th.V,10,1; Nov. Val. III,34,19; Lex.V., XI,2,1 = C.Th.IX, 17 (rubr.). 
En suma, la España visigoda, conoció los textos justinianeos, así la siguiente cuestión es si efectivamente los conoció también San Isidoro.

\section{LA BIBLIOTECA ISIDORIANA}

Isidoro nunca se cansó de buscar y coleccionar libros, así consiguió que todo lo mejor, de los siglos que le precedieron, estuviera en su biblioteca, ejemplares traídos de Grecia, de Italia, de Alejandría, de todos los lugares, incluido, por supuesto, Bizancio. En su librería,.los libros, estaban ricamente encuadernados, pulcramente ilustrados y esmeradamente escritos. Los más preciados, como la Biblia, los tenía en un estuche de maderas aromáticas y otros, también muy apreciados por él, los tenía en unos estuches de ricos metales.

Como complemento, junto a la biblioteca, instaló un taller de copistas. Organizó su escritorio (el primero del que hay noticias en España) ${ }^{17}$ a modo de imprenta. Declaró la biblioteca como el lugar más importante junto con la Iglesia. Ordenó que el monje que maltratase un libro fuese amonestado y castigado por ello, a ejercer de copista los fines de semana. Todos allí tenían que aspirar a la perfección, el que combinaba las tintas, el que preparaba la vitela, el que adornaba las iniciales, el que ilumina los folios, ... todos. En las salas, ordenó silencio y colocó las siguientes leyendas: "Amigo, si sabes copiar y pintar dos, tres y cuatro veces mejor, tu obligación es hacerlo». "Si eres capaz de comprender donde estás, calla. El copista no sufre a su lado a un hablador», o "El que estuviere aqui media hora ocioso, sea suspendido y reciba dos azotes"

San Isidoro tuvo la biblioteca más rica de su tiempo y no se sabe de nadie que la iguálase, entre otras cosas, porque muchos de los libros que él leyó y extractó, desaparecieron para siempre, y lo que sabemos de ellos es únicamente por sus extractos. Allí había de todo: teología, historia, aritmética, política, religión, leyes; como dice Pérez de Urbel ${ }^{18}$, los decretales imperiales tenían su complemento en las decretales de los papas; los Santos Padres convivían con los autores clásicos, las actas conciliares se juntaban con las leyes de juristas romanos.

\footnotetext{
17 Cfr. PÉREZ DE URBEL, Justo, San Isidoro. Su vida,... cit. p.84

18 Vid. PÉREZ DE URBEL, Justo, San Isidoro, Barcelona 1940, p.14.
} 
El Doctor de las Españas, como buen bibliófilo, leía y traducía los textos griegos, mejor incluso que San Gregorio el Magno, que había vivido durante un tiempo en Constantinopla, antes de acceder al Papado (590-604), donde hizo amistad con San Leandro, hermano de San Isidoro, helenista, que pasó tres años en Bizancio, concretamente entre los años 584 y 586, y que, según parece, también sabía griego.

El amor de Isidoro por la lectura era constante, él mismo escribe a su hermana Florentina: «Ruégote, que fomentes en ti constantemente la afición a leer; pues cuanto más asiduo es uno en el trato de los santos libros, tanto mayor será la inteligencia que saque de ellos, de la misma manera que cuanto más se cultiva un campo, más abundante fruto produce. Por muy tardos que tenga un hombre los sentidos, siempre llegará a comprender algo de los sagrados misterios, si es tenaz en la lectura» ${ }^{19}$.

El metropolitano de Sevilla, fue un ávido lector que aprovechó los textos antiguos, con una metodología paciente, laboriosa y sistemática. Leía metódicamente, infatigablemente, extractando lo que más le interesaba y le impresionaba, ordenándolo primero en su memoria; pero también en sus cuadernos de notas y en sus apuntes, dispuestos cuidadosamente y escrupulosamente catalogados. El orden, que más tarde intentará establecer en la Iglesia y en el Estado, le hace reinar desde ahora en su inmenso fichero. Busca libros por todas partes, libros clásicos y patrísticos, latinos y griegos, poéticos y jurídicos, científicos y filosóficos. Un libro nuevo era para él una gracia de Dios y la mayor de las venturas. Se llena de tristeza al pensar que no ha podido reunir todas las obras de San Agustín, y hablando de San Gregorio Magno, dice, inconsolable: «Mejor suerte que yo tendrá aquel a quien Dios conceda el deleite de saborear todos sus escritos» ${ }^{20}$.

Así, el conocimiento romanístico de San Isidoro nos es confirmado, pues, por su biblioteca, por las colecciones de libros de derecho romano que tenía, inclusive, como demuestra su gran obra enciclopédica, los de historia y arqueología del derecho romano. Igualmente, el conocimiento de los textos justinianeos, por parte de San Isidoro, nos es confirmado por su entorno, es decir, por la ocupación bizantina de parte de la península; por las relaciones de la España de los siglos V, VI y VII con Oriente, que fueron muy frecuentes y estrechas; porque varios eclesiásticos españoles insignes, entre ellos

19 Vid. Admonitiunculae ad sororem, cap.XIII

20 Vid. PÉREZ DE URBEL, Justo, San Isidoro. Su vida,... cit. p.72. 
el famoso cronista de origen godo Juan de Valclara, viajaron por Oriente y por Bizancio; porque algunos de los obispos españoles de la época fueron griegos, por ejemplo Paulo y Vital, que ocuparon sucesivamente la sede de Mérida; así como por los viajes de su hermano a Constantinopla, y porque las relaciones de San Isidoro con los bizantinos, han tenido que ser continuas. Su familia, y quizás él ${ }^{21}$, provenían de Cartagena, de donde serían expulsados, por los bizantinos, a los que tuvo por vecinos casi toda su vida, hasta el 624, y quizás hasta fue su súbdito, pues cuando dominaban Andalucía, llegaron, al parecer, a Sevilla. También está documentado que su hermano San Leandro, para interesar por la causa de San Hermenegildo a los bizantinos, estuvo en Bizancio, de donde trajo libros - justinianeospara la común biblioteca.

A esto hay que añadir que, en la Ley 10 lib.II tit.I del Liber Judiciorum, Recesvinto alude a la legislación bizantina, y que, en la Lex Visigothorum, como hemos visto, son bastantes los pasos de las colecciones justinianeas. Además, en el año 603, siendo San Isidoro arzobispo de Sevilla, San Gregorio, envió a España un Abogado defensor, para resolver la cuestión de Genaro, obispo de Málaga, en poder de los bizantinos. Como es sabido, San Gregorio, dio a su representante una instrucción para el proceso. No es posible que San Isidoro, tan interesado en la causa, y tan diligente, no conociese del asunto, la instrucción y las fuentes.

Así, debemos admitir que el derecho bizantino, es decir, el derecho justinianeo (ya que se trata de la época Justiniano), fue aplicado en España ${ }^{22}$ y conocido por los legisladores y jurisconsultos visigodos, y acerca de las fuentes de las que San Isidoro tomó sus nociones jurídicas, como sostienen Larraona y Tabera ${ }^{23}$, podemos establecer lo siguiente: No es posible que San Isidoro no haya conocido las colecciones justinianeas.

En suma, San Isidoro -al igual que los legisladores y los jurisconsultos visigodos - conoció los textos justinianeos, pero - y ahí radica la cuestión- apenas los utilizó. ¿Qué poderoso motivo tenía para no usar las importantes fuentes justinianeas?

${ }^{21}$ Al día de hoy, los investigadores no ha podido precisar si San Isidoro nació en Cartagena o en Sevilla.

${ }_{22}$ Cfr. UREÑA, Rafael de, Historia de ... cit.., p.300

${ }^{23}$ Cfr. LARRAONA Y TABERA, p.111 


\section{LA TEOLOGÍA ISIDORIANA}

Con la conversión de Recaredo, desaparecen las dos principales herejías, el priscilianismo y el arrianismo, y San Isidoro, conocedor de todas las ciencias de la antigüedad, concibe la creación de un verdadero tratado de teología, que vertebre decisivamente la unidad nacional. San Isidoro escribió una de sus obras más bellas: «De las diferencias de las palabras y los conceptos», donde establece la diferencia entre Trinidad (diversidad de personas) y Unidad (sustancia inseparable de la deidad); porque en las personas hay distinción y en la Divinidad, no ${ }^{24}$.

Además de "De las diferencias de las palabras y los conceptos", San Isidoro escribió otro manual más metódico que, iba a tener una influencia decisiva en la historia de la teología, son los tres libros de las Sentencias, que representa la primera sistematización del dogma y de la moral cristiana. Así surgió el primer ensayo de literatura teológica, que sería ordenado por los escolásticos venideros, pero el camino ya había quedado trazado y el sistema de San Isidoro no sería modificado hasta siglos después ${ }^{25}$.

Como es bien sabido, el Doctor de las Españas, concedió gran importancia a los torneos teológicos. En este sentido, resulta de especial relevancia, el segundo Concilio de Sevilla, en el año 619, donde San Isidoro luchó contra los acéfalos (sin cabeza), a los cuales identificaba con los monofisistas, y entre cuyas autoridades se encontraba Justiniano, el emperador acéfalo, y San Cirilo de Alejandría, en quien se han apoyado los monofisistas de todos los tiempos.

San Isidoro, venció al obispo acéfalo, con gran abundancia de documentación y una gran fuerza dialéctica y una gran astucia, ya que la mayor parte de sus citas provenían del emperador Justiniano. El obispo acéfalo, obviamente, hubo de declararse vencido y así, San Isidoro, alejó de España el peligro monofisista.

Los escenarios en los cuales se desarrollaron estas luchas teológicas fueron, como manifiesta el jurista e historiador García Villada ${ }^{26}$, los Concilios-Cortes de Toledo, los cuales constituyen una institu-

${ }^{24}$ La diferencia entre lo humano y lo divino, le lleva a establecer una de sus máximas: «La justicia es ley divina, el derecho ley humana " (Etimología, Libro V, Capítulo II).

${ }_{25}$ Cfr. PÉREZ DE URBEL, Justo, San Isidoro. Su vida,... cit. p.190-202.

${ }^{26}$ Cfr. GARCÍA VILLADA, Zacarias, Historia eclesiástica de España, tomo II, Madrid 1932, p.126 
ción típicamente visigoda, sin precedentes en ningún país, sin exceptuar las Galias ni Bizancio, que convocados por el Rey y constituidos por los Obispos, así como por los magnates godos, legislaron sobre materias civiles y religiosas.

Desde su cátedra episcopal, San Isidoro, prosiguió la lucha contra la ignorancia, otorgando una enorme importancia a la Educación, así en el Concilio de Toledo, decretó que en cada diócesis se estableciera una escuela. Esto ocurrió siglos antes de que Carlomagno decretara algo similar (Farmer, 219) ${ }^{27}$. En la práctica, como señala Pérez de Urbel ${ }^{28}$, los escolares estudiaban los salmos de memoria. El maestro pronunciaba de memoria y los niños repetían cada verso, una, dos, veinte veces, y así, poco a poco, los ciento cincuenta salmos iban entrando en las tiernas cabecitas y a los salmos debían seguir, según un canon del Concilio de Toledo, los cánticos y los himnos de la liturgia. Más tarde, se pasaba al estudio del Trivio y el Cuadrivio, o como dice San Isidoro, de las siete artes liberales.

En este orden de cosas, los teólogos carolingios, que tanto discutieron acerca de la Predestinación (entendían que Dios predestina a la condenación y al pecado), invocaron la autoridad de San Isidoro que había establecido que no existe la predestinación al pecado, porque Dios no puede quererlo sino sólo permitirlo.

En las escuelas del imperio de Carlomagno, se suscitó otra cuestión de gran importancia: la Eucaristía. También en esta discusión se acudió a San Isidoro, que había establecido que "el que cesó de pecar, no cese de comulgar ${ }^{29}$.

Como hemos dicho, el metropolitano de Sevilla, concibe la creación de un verdadero tratado de teología, que vertebre decisivamente la unidad nacional, y cuando en el 633, preside el IV Concilio de Toledo $^{30}$, otorga a la Iglesia hispana una legislación que asegurase la supervivencia de sus instituciones, hemos de recordar que, en este tiempo, el obispo estaba investido tanto de personalidad religiosa como política, lo cual le posibilitaba para influir en los actos de gobierno; pero, además, poco antes de morir presentó a la España visi-

27 Vid. Página Web http://www.humnet.ucla.edu/santiago/SI_Bio.html

${ }_{28}$ Cfr. PÉREZ DE URBEL, Justo, San Isidoro. Su vida,... cit. p. 98.

${ }^{29}$ Vid. De ecclesiasticis officiis, lib. cap. XVIII.

30 Hacía cuarenta y cuatro años que no había habido ningún concilio general en España, San Isidoro era ya un anciano, así entendemos que no desaprovechase la oportunidad para cumplir su sueño de juventud: asegurar la perdurabilidad de la obra de unificación que tanto le preocupó. 
goda la ingente colección canónica que, con el nombre la Hispana, tuvo fuerza de ley en la península hasta fines del siglo XII, así como establece Urbel ${ }^{31}$, lo que San Isidoro, había hecho en los años anteriores, recogiendo y condensando la ciencia sagrada y profana, lo hace ahora en lo que se refiere a las leyes canónicas y, España, por medio de él, se constituye en guardadora y transmisora de la tradición cultural en todos sus aspectos a las nuevas sociedades que se están formando en Europa.

Cuando Carlomagno mandó llamar a su corte en el 782 a Alcuino de York, éste enseñó las obras de San Isidoro, en la Escuela Palatina, hasta que en el 796 se retiró a la ciudad de Tours. La Hispana es, en sus manos, el signo de la reforma eclesiástica, y el texto isidoriano de la Biblia, propagado por él, en las iglesias carolingias, ayuda al maestro Alcuino en la revisión que prepara, y aunque más tarde la Vulgata, revisada por Alcuino, arrinconará el viejo texto isidoriano, la impronta del obispo metropolitano de Sevilla había quedado fijada para siempre.

\section{A MODO DE CONCLUSIÓN}

El derecho justinianeo no tuvo una influencia inmediata, pues como afirma García Garrido ${ }^{32}$, el derecho vulgar, representa la forma bajo la que ha pervivido el derecho romano en la práctica occidental, al menos hasta el siglo viII. Así, para el legislador de Sevilla, la cuestión era que el emperador de Bizancio, Justiniano, se había atrevido a legislar incluso en materias teológicas, y el Doctor de las Españas pensaba que los españoles debían estar sujetos a un mismo rey y a una misma religión, mientras que los poderes civiles debían estar dentro de la disciplina de la religión ${ }^{33}$ y viceversa, pero el metropolitano de la Bética no quería la supremacía del Estado ni tampoco deseaba la de la Iglesia, así entendía que el Estado debía estar subordinado a la Iglesia en lo Espiritual, y la Iglesia al Estado en los negocios temporales.

Justiniano, representa el modelo político llamado cesaropapismo, que declaraba, bajo su única autoridad, que su gobierno ponía el mismo empeño en los asuntos temporales que en la defensa de los

31 Cfr. PÉREZ DE URBEL, Justo, San Isidoro. Su vida,... cit. p.232.

32 Vid. GARCÍA GARRIDO, Manuel Jesús, Las actuales orientaciones romanísticas, Derecho Notarial 39, 1963, p. 27

33 Vid. Sentencias, lib. 3 cap. XLIX. 
dogmas divinos. Frente a esta concepción de la parte oriental, donde la Iglesia y el Imperio formaron una simbiosis en la que no se podía diseccionar fácilmente uno de otro, como afirma Federico Fernández de Buján ${ }^{34}$, el emperador Carlomagno, recupera el sentido genuino del poder político existente en la parte occidental del Imperio, quedando establecido el orden político del medievo sustentado en virtud de la potestad real del emperador, regalis potestas, y de la autoridad moral del Papa, sacrata auctoritas.

Así, a mi juicio, acerca de la cuestión de si San Isidoro usó los textos justinianeos, hay que concluir en primer término, que sin duda los conoció y, en segundo lugar, que si no los utilizó —o los utilizó muy poco- fue con la finalidad de frenar los excesos de Justiniano o, más concretamente, del cesaropapismo. Por este motivo, unida España (hispanorromanos y visigodos), mediante el cristianismo, otorgó a la Iglesia hispana de una legislación que garantizase la supervivencia de sus instituciones, y estableció que el rey y la Iglesia habían de estar en estrecha colaboración. El rey de rodillas delante de los obispos y los obispos de rodillas delante del rey, como sucedió en los últimos concilios de Toledo. Y resolvió el mantenimiento de la Iglesia por el Pontificado, mediante su cabeza visible: el pontífice romano. Así, cuando ningún obispo encontraba en las Escrituras razones evidentes, para considerar a San Pedro como superior a los demás apóstoles, San Isidoro, les contesta: «Tu es Petrus y el Pasce agnos meos», añadiendo: «Es verdad que la dignidad pontifical pasó a los obispos de todas las iglesias del mundo, sin embargo permanece de una manera especial en el pontífice romano, como cabeza superior a los demás miembros $»^{35}$.

El obispo metropolitano de Sevilla, dejó un inmenso legado que fue recogido por sus discípulos San Braulio ${ }^{36}$, San Ildefonso, por los sucesivos Concilios de Toledo, y también, con diferente intensidad, por los obispos carolingios, que se inspiraron en él para implantar un nuevo sistema educativo y solucionar sus discusiones teológicas acerca de la Predestinación, la Eucaristía o la Biblia. De hecho, Alcuino de York, principal cabeza visible de la academia palatina carolingia,

${ }^{34}$ Vid. FERNÁNDEZ DE BUJÁN, Federico, Sistema Contractual Romano, Madrid 2004, p.464-465.

${ }^{35}$ Isidori ad Eugenium episcopum, ep. VIII

36 Los cuales nos confirman su admiración por San Isidoro: «Tus libros nos dijeron quienes éramos y dónde nos hallabamos» (San Braulio), "El que le oía una vez, quedaba siempre con ansía de oírle de nuevo» (San Ildefonso), "El hombre más docto que ha aparecido en los últimos tiempos, cuyo nombre ha de pronunciarse con reverencia» (VIII Concilio de Toledo). 
inculcó a sus discípulos de Aquisgrán y de Tours, el respeto por las enseñanzas de San Isidoro a quien consideraba el doctor, brillante y clarísimo, de todas las iglesias de la elocuencia latina.

En suma, San Isidoro de Sevilla, fue el gran inspirador de Carlomagno y su pretendida renovación del Imperio Romano de Occidente, y sin él, como señala Urbel ${ }^{37}$, la época de Carlomagno sería apenas explicable ${ }^{38}$.

37 Cfr. PÉREZ DE URBEL, Justo, San Isidoro. Su vida,... cit. p.280.

38 En el año 936, finalizado el imperio carolingio, Otón I se proclama, simbólicamente, continuador del Imperio Romano de Occidente, siendo el primer emperador del Sacro Imperio Romano Germánico. Los sucesivos emperadores del Sacro Imperio que, como es bien sabido duraría hasta 1806, aplicaron el Corpus de Justiniano, el cual junto con la Revolución Francesa y Napoleón, configuraría los aspectos jurídicos, religiosos, políticos, y sociales, de la Europa actual. 
ANEXO: TABLA CRONOLÓGICA

\begin{tabular}{|c|c|c|}
\hline \multirow{2}{*}{$\begin{array}{c}476 \\
\text { Caída del Imperio Romano } \\
\text { de Occidente }\end{array}$} & & $\begin{array}{c}482 \\
\text { Nace JUSTINIANO }\end{array}$ \\
\hline & & $\begin{array}{c}529 \\
\text { CÓDIGo de Justiniano } \\
533 \\
\text { INSTITUCIONES de Justi- } \\
\text { niano } \\
533 \\
\text { DIGESTO }\end{array}$ \\
\hline $\begin{array}{l}551-567 \\
\text { ATANAGILDO, pide ayuda } \\
\text { al emperador bizantino Jus- } \\
\text { tiniano }\end{array}$ & & $\begin{array}{c}554 \\
\text { JUSTINIANO, establece la } \\
\text { provincia bizantina de Es- } \\
\text { paña en los territorios ocu- } \\
\text { pados (franja de Denia a } \\
\text { Gibraltar, Baeza, Jaén, An- } \\
\text { tequera, Cartagena) }\end{array}$ \\
\hline \multirow{3}{*}{$\begin{array}{l}572-586 \\
\text { LEOVIGILDO, fundador } \\
\text { del reino visigodo de Tole- } \\
\text { do, intentó la unidad reli- } \\
\text { giosa del reino, a base de } \\
\text { doctrinas arrianas, pero } \\
\text { fracasó. Su hijo SAN HER- } \\
\text { MENEGILDO, falleció en } \\
\text { prisión en el 585, por con- } \\
\text { vertirse al catolicismo y ne- } \\
\text { garse a volver al arrianismo }\end{array}$} & $\begin{array}{c}556-560 \\
\text { Nace ISIDORO }\end{array}$ & \multirow[t]{3}{*}{$\begin{array}{c}565 \\
\text { Fallece el emperador JUS- } \\
\text { TINIANO. }\end{array}$} \\
\hline & $\begin{array}{c}562 \\
\text { Mueren los padres de ISI- } \\
\text { DORO }\end{array}$ & \\
\hline & $\begin{array}{c}578 \\
\text { LEANDRO, hermano de Isi- } \\
\text { doro, es nombrado obispo } \\
\text { de Sevilla }\end{array}$ & \\
\hline \multirow{4}{*}{$\begin{array}{l}586-601 \\
\text { RECAREDO, hijo y sucesor } \\
\text { de Leovigildo, modifica la } \\
\text { política de su padre y se } \\
\text { convierte, junto con el pue- } \\
\text { blo visigodo, al catolicismo }\end{array}$} & $584-586$ & \multirow{4}{*}{$\begin{array}{c}590-604 \\
\text { Accede al Papado GREGO- } \\
\text { RIO I, llamado el Magno, } \\
\text { célebre por sus escritos teo- } \\
\text { lógicos amigo de LEAN- } \\
\text { DRO, y también de ISIDO- } \\
\text { RO }\end{array}$} \\
\hline & $\begin{array}{l}\text { LEANDRO, viaja a Constan- } \\
\text { tinopla, donde hace amistad } \\
\text { con el futuro Papa Gregorio } \\
\text { I, llamado el Magno. }\end{array}$ & \\
\hline & $\begin{array}{l}589 \\
\text { ISIDORO acompaña a su } \\
\text { hermano LEANDRO, obispo } \\
\text { de Sevilla, al } \text { HI CONCILIO } \\
\text { DE TOLEDO, donde se rati- } \\
\text { fica la fusión de visigodos e } \\
\text { hispanorromanos. Leandro } \\
\text { pasa a ser asesor permanen- } \\
\text { te del rey. }\end{array}$ & \\
\hline & $\begin{array}{c}599 \\
\text { Fallece su hermano LEAN- } \\
\text { DRO e Isidoro le sustituye } \\
\text { en la silla episcopal }\end{array}$ & \\
\hline
\end{tabular}




\begin{tabular}{|c|c|c|}
\hline \multirow[t]{2}{*}{$\begin{array}{c}612-621 \\
\text { SISEBUTO, antiguo alum- } \\
\text { no de Isidoro, sube al trono }\end{array}$} & \multirow{2}{*}{$\begin{array}{l}612 \\
\text { ISIDORO fija la legislación } \\
\text { nacional (Fuero Juzgo) y } \\
\text { auspicia la unión del poder } \\
\text { real con la Iglesia, para fre- } \\
\text { nar los excesos del ultraca- } \\
\text { tólico SISEBUTO }\end{array}$} & $\begin{array}{c}620 \\
\text { Comienzan a circular co- } \\
\text { pias incompletas y altera- } \\
\text { das de la primera redacción } \\
\text { de LAS ETIMOLOGÍAS }\end{array}$ \\
\hline & & $\begin{array}{c}625 \\
\begin{array}{c}\text { Los bizantinos son expulsa- } \\
\text { dos de Hispania }\end{array}\end{array}$ \\
\hline \multirow{4}{*}{$\begin{array}{c}631-636 \\
\text { SISENANDO, al igual que } \\
\text { Sisebuto, antiguo alumno } \\
\text { de Isidoro en la Escuela de } \\
\text { Sevilla, sube al trono }\end{array}$} & $\begin{array}{l}\quad 628 \\
\text { Fallece su hermano FUL- } \\
\text { GENCIO, obispo de Ecija }\end{array}$ & \multirow{2}{*}{$\begin{array}{l}633 \\
\text { BRAULIO, discípulo de Isi- } \\
\text { doro y obispo de Zaragoza, } \\
\text { ordena y divide la redac- } \\
\text { ción definitiva de } L A S E T I- \\
M O L O G I ́ A S, \text { tal y como han } \\
\text { corrido por toda Europa }\end{array}$} \\
\hline & $\begin{array}{c}631 \\
\text { Fallece su hermana FLO- } \\
\text { RENTINA }\end{array}$ & \\
\hline & $\begin{array}{c}633 \\
\text { ISIDORO preside el } N \\
\text { CONCILIO DE TOLEDO, } \\
\text { - donde se acuerda que el rey } \\
\text { y la Iglesia se apoyen mu- } \\
\text { tuamente }\end{array}$ & \multirow{2}{*}{$\begin{array}{l}1472 \\
\text { Se imprimen por primera } \\
\text { vez, en Augsburgo, LAS } \\
\text { ETIMOLOGÍAS que, junto } \\
\text { con LA BIBLIA, es el libro } \\
\text { más leído y copiado de Eu- } \\
\text { ropa (Âmsterdam, Basilea, } \\
\text { Venecia, París, Friburgo...). }\end{array}$} \\
\hline & $\begin{array}{c}634 \\
\text { En el mes de abril, fallece } \\
\text { SAN ISIDORO, El Doctor de } \\
\text { las Españas }\end{array}$ & \\
\hline
\end{tabular}

